\title{
Correlation of Serum and Urine Vitamin $B_{12}$
}

\author{
J. F. ADAMS,* V.R.D., M.D., F.R.C.P.(ED. AND GLASG.)
}

\begin{abstract}
ummary: The relation between the serum vitamin $\mathbf{B}_{12}$ level and the daily loss of vitamin $B_{12}$ in urine was examined in patients with normal serum vitamin $B_{12}$ levels and in patients suffering from vitamin $B_{12}$ deficiency. A linear correlation was found between the two measurements, suggesting that the serum vitamin $B_{12}$ level is a governing factor in the urinary loss of vitamin $B_{12}$. The contribution by this loss to the total loss of vitamin $B_{12}$ from the body is small under normal circumstances but becomes quantitatively more important with the depletion of body stores.
\end{abstract}

\section{Introduction}

Vitamin $\mathrm{B}_{1: 2}$ is lost from the body in urine and faeces. Little is known about the factors that determine the magnitude of the loss in either medium or of the relative losses in health and disease. Information on these points was sought by examining the relation between the serum vitamin $B_{12}$ level and the daily loss of vitamin $B_{12}$ in urine in subjects with normal serum vitamin $B_{12}$ levels and in those with vitamin $B_{12}$ deficiency.

\section{Materials and Methods}

Material for study was obtained from 114 male and female inpatients. Of these, 97 had diseases not known to affect vitamin $\mathbf{B}_{12}$ metabolism; in particular, patients with renal, hepatic, or haematological disorders were excluded. The remaining 17 had untreated vitamin $B_{12}$-deficiency states subsequently diagnosed as due to pernicious anaemia (15 cases), partial gastrectomy ( 1 case), and dietary deficiency (1 case).

Urine was collected direct or via filter funnel into acidwashed sterile dark glass bottles. Aliquots of serum and urine were stored at $-20^{\circ} \mathrm{C}$. immediately after collection until assay by the method of Hutner, Bach, and Ross (1956), with Euglena gracilis $\mathrm{Z}$ strain as the test organism.

Recovery experiments with added cyanocobalamin were performed on urine samples from patients on drug therapy.

\section{Results}

Recovery experiments did not show inhibition of growth of the test organism by any sample of urine tested. A linear correlation was found between the serum vitamin $B_{12}$ level in pg./ml. (x) and the 24-hour urine vitamin $B_{12}$ in $\mathrm{ng}$. (y), the regression equation being $y=62.5784+0.2312 \times($ Fig. 1 ) and the coefficient of correlation being $0.44(P<0.001)$. The distribution of daily urine vitamin $B_{1:}$ values was skewed (Fig. 2).

\section{Discussion}

The correlation between the microbiological activity of serum and urine suggests that the serum vitamin $\mathbf{B}_{1:}$ level is a

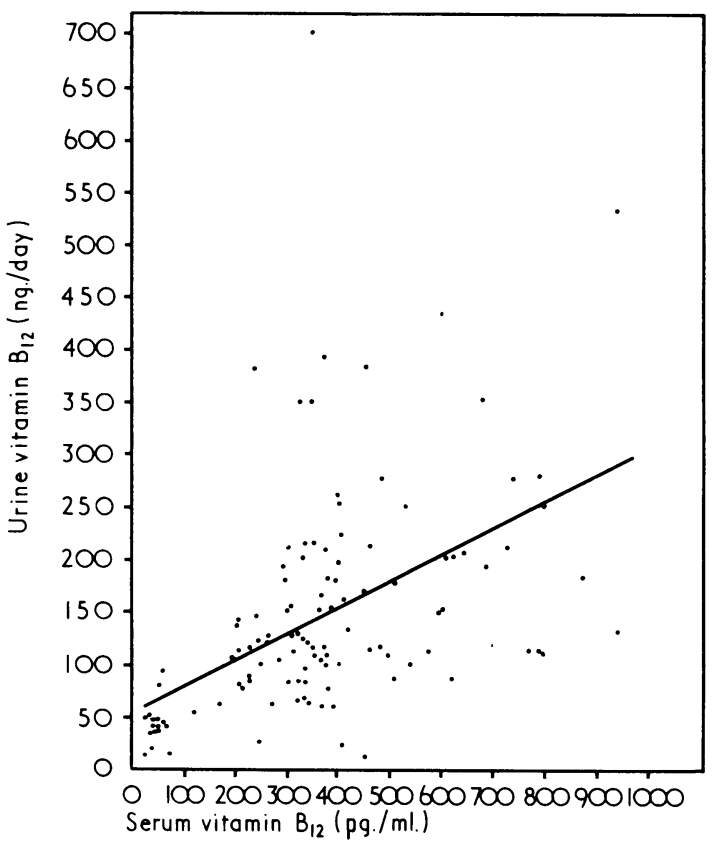

Fig. 1.-Correlation of serum vitamin $\mathrm{B}_{12}$ and daily urine vitamin $\mathbf{B}_{1}$.

governing factor in the amount of vitamin $B_{12}$ lost in the urine. The precise nature of the relation is not clear. An obvious explanation is that vitamin $B_{12}$ is dissociated from the plasma-binding proteins transcobalamins I and II (Hall and Finkler, 1962, 1965), and excreted by glomerular filtration. It is also possible that the urine vitamin $B_{12}$ may be related to

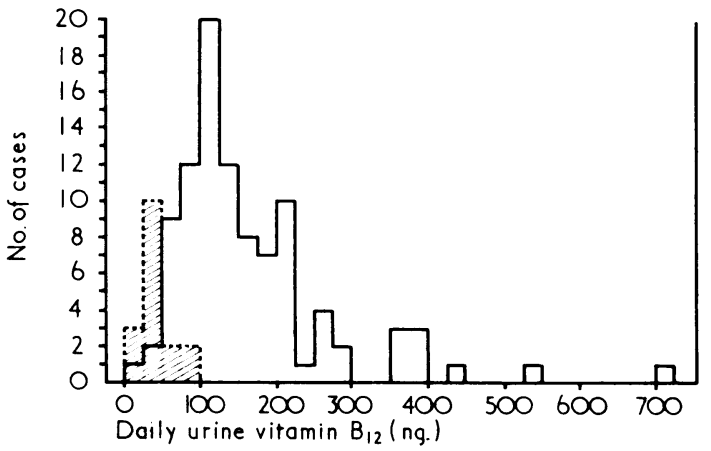

FIG. 2.-Distribution of daily urine vitamin $B_{12}$ values. The shaded areas represent values for patients with vitamin $B_{12}$ deficiency states; the area delineated by the unbroken line represents the values for normal subjects.

the transcobalamin II- $\mathrm{B}_{12}$ complex, which has a molecular weight in the region of 40,000 (Hom, Olesen, and Lous, 1966; Hom and Olesen, 1967). Neither mechanism would be incompatible with the observation that cigarette smoking has a significant effect on the urine, but not the serum vitamin $\mathbf{B}_{12}$ level (Linnell, Smith, Smith, Wilson, and Matthews, 1968).

The range of daily urine vitamin $B_{1: 2}$ values in this series is 
greater than that found by Register and Sarett (1951) but not out of keeping with those reported by Girdwood (1951), Mollin and Ross. (1952), Heinrich (1954), Jones, Mills, and Capps (1957), and Linnell et al. (1968) in smaller series of normal subjects and by Girdwood (1951), Mollin and Ross (1952), and Heinrich (1954) in patients with pernicious anaemia. The mean value of daily urine vitamin $B_{12}$ in the nonvitamin $B_{12}$-deficient subjects was $164 \mathrm{ng}$./day, which is higher than that previously found by direct measurement but less than that calculated by Hall (1964) from kinetic studies. The significance of mean values is doubtful, however, as the distribution of daily urine vitamin $B_{12}$ values is lognormal, as is the distribution of serum vitamin $B_{12}$ levels in normal subjects (Gräsbeck 1961).

The results are of interest in relation to the proportionate losses of vitamin $\mathrm{B}_{12}$ from the body by the renal and intestinal routes. Serial whole-body measurements in normal and in vitamin $B_{12}$-deficient subjects given radioactive cobalamins orally or parenterally have shown that the daily loss of vitamin $B_{12}$ from the body is a function of the total body stores amounting to $0.1-0.2 \%$ of stores per day (Heyssel, Bozian, Darby, and Bell, 1966; Adams and Boddy, 1968; Boddy and Adams, 1968). Thus with stores of 2,000 $\mu \mathrm{g}$. the daily loss will be $2-4 \mu \mathrm{g}$.: from the results it is clear that the contribution to this total by the urine loss will be small. With a fall in body stores to say $100 \mu \mathrm{g}$. and a fall in serum vitamin $B_{12}$ level to subnormal values the total daily loss will amount to 100 to $200 \mathrm{ng}$., and the contribution to this total by the urinary loss will be proportionately greater than in normal circumstances and may then account for half of the total loss.

The correlation between the serum and urine vitamin

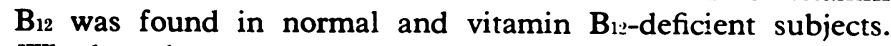
Whether the measurements are correlated in disease states accompanied by a high serum vitamin- $B_{12}$ level, such as chronic myeloid leukaemia (Beard, Pitney and Sanneman, 1954; Mollin and Ross, 1955; Miller and Sullivan, 1958), renal failure (Matthews and Beckett, 1962), or hepatic disease (Holdsworth,
Atkinson, Dossett, and Hall, 1964; Neale, Caughey, Mollin, and Booth, 1966; Rachmilewitz and Eliakim, 1968) has not been investigated, and further study of this aspect may be necessary to comprehend the problem of vitamin $\mathbf{B}_{1:}$ balance in disease states.

\section{REFERENCES}

Adams, J. F., and Boddy, K. (1968). Fournal of Laboratory and Clinical Medicine, 72, 392.

Beard, M. F., Pitney, W. R., and Sanneman, E. H. (1954). Blood, 9, 789. Boddy, K., and Adams, J. F. (1968). American fournal of Clinical Nutrition, 21, 657.

Girdwood, R. H. (195i). Edinburgh Medical fournal, 58, 309.

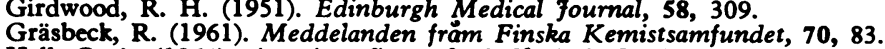
Gräsbeck, R. (1961). Meddelanden fram Finska Kemistsamfundet, 70,

Hall, C. A., and Finkler, A. E. (1962.) fournal of Laboratory and Clinical Medicine, 60, 765.

Hall, C. A., and Finkler, A. E. (1965). Fournal of Laboratory and Clinical Medicine, 65, 459 .

Heinrich, H. C. (1954). Klinische Wochenschrift, 32, 867.

Heyssel, R. M., Bozian, R. C., Darby, W. J., and Bell, M. C. (1966) American foumal of Clinical Nutrition, 18, 176.

Holdsworth, C. D., Atkinson, M., Dossett, J. A., and Hall, R. (1964) Gut, 5, 601 .

Hom, B., and Olesen, H. (1967). Scandinavian fournal of Clinical and Laboratory Investigation, 19, 269.

Hom, B., Olesen, H., and Lous, P. (1966). Fournal of Laboratory and Clinical Medicine, 68, 958.

Hutner, S. H., Bach, M. K., and Ross, G. I. M. (1956). Fournal of Protozoology, 3, 101.

Jones, P. N., Mills, E. H., and Capps, R. B. (1957). Fournal of Laboratory and Clinical Medicine, 49, 910.

Linnell, J. C., Smith, A. D. M., Smith, C. L., Wilson, J., and Matthews, D. M. (1968). British Medical fournal, 2, 215

Matthews, D. M., and Beckett, A. G. (1962). fournal of Clinical Pathology, $15,456$.

Miller, A., and Sullivan, J. F. (1958). fournal of Clinical Investigation, 37, 556.

Mollin, D. L., and Ross, G. I. M. (1955). British fournal of Haematology, 1,155 .

Mollin, D. L., and Ross, G. I. M. (1952). Fournal of Clinical Pathology, 5, 129.

Neale, G., Caughey, D. E., Mollin, D. L., and Booth, C. C. (1966). British Medical Fournal, 1, 382.

Rachmilewitz, M., and Eliakim, M. (1968). Israel fournal of Medical Science, $4,47$.

Register, U. D., and Sarett, H. P. (1951). Proceedings of the Society for Experimental Biology and Medicine, 77, 837.

\title{
Effect of Ergotamine and Ergometrine on Forearm Venous Compliance in Man
}

\author{
O. G. BROOKE, ${ }^{*}$ M.B., B.S., M.R.C.P. ; B. F. ROBINSON, $†$ M.D., M.R.C.P.
}

\begin{abstract}
ummary: The effect of ergotamine and ergometrine on the venous compliance of the forearm has been studied in normal persons. Ergotamine tartrate $(0.25 \mathrm{mg}$. intravenously) led to a fall in venous compliance amounting to $49 \%$ on average, while ergometrine maleate ( $0.25 \mathrm{mg}$. intravenously) caused a reduction of $41 \%$; these changes were statistically significant. The potent venoconstrictor action of these ergot alkaloids appears to be a major component of the circulatory response to small doses and may be important in provoking the harmful cardiovascular side-effects (such as angina and pulmonary oedema) that are sometimes observed in patients with pre-existing heart disease.
\end{abstract}

\section{Introduction}

The ergot alkaloids have been widely used in medicine and obstetrics for many years, and the risk of gangrene from excessive dosage is well recognized (Goodman and Gilman,
1965). There is, however, some risk of harmful side-effects with standard clinical doses in patients with certain cardiac abnormalities. Thus ergotamine may aggravate the symptoms of angina pectoris in patients with ischaemic heart disease (Friedman et al., 1959), while ergometrine is believed to carry some risk of precipitating pulmonary oedema if given post partum to patients with mitral stenosis (Barnes, 1965). The mechanism of these untoward effects is not clear, though possible explanations have been advanced.

In analysing the circulatory side-effects of the ergot alkaloids it is important to understand their action on the peripheral circulation. The complex effect of these drugs on the arterial system has been studied in detail (Dale, 1906; Rothlin, 1947; Bluntschli and Goetz, 1948; Barcroft et al., 1951), but their effect on the venous system has received little attention. We

\footnotetext{
* Senior House Officer.

† Senior Lecturer in Medicine.

Medical Unit, St. George's Hospital, London S.W.1.
} 